ASTHMA

\title{
Efficacy of low and high dose inhaled corticosteroid in smokers versus non-smokers with mild asthma
}

\author{
J E M Tomlinson, A D McMahon, R Chaudhuri, J M Thompson, S F Wood, N C Thomson
}

Thorax 2005;60:282-287. doi: 10.1136/thx.2004.033688

See end of article for authors' affiliations

Correspondence to:

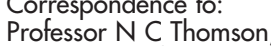
Department of Respiratory Medicine, Division of Immunology, Infection and Inflammation, Western Infirmary, Glasgow G1 1 6NT UK; n.c.thomson@ clinmed.gla.ac.uk

Received 25 August 2004 Accepted 3 February 2005

\begin{abstract}
Background: Cigarette smokers with asthma are insensitive to short term inhaled corticosteroid therapy, but efficacy when given for a longer duration at different doses is unknown.

Methods: Ninety five individuals with mild asthma were recruited to a multicentre, randomised, double blind, parallel group study comparing inhaled beclomethasone in doses of $400 \mu \mathrm{g}$ or $2000 \mu \mathrm{g}$ daily for 12 weeks in smokers and non-smokers. The primary end point was the change in morning peak expiratory flow (PEF). Secondary end points included evening PEF, use of reliever inhaler, number of asthma exacerbations, spirometric parameters, and asthma control score.

Results: After 12 weeks of inhaled beclomethasone there was a considerable difference between the morning PEF measurements of smokers and non-smokers with asthma $(-18(95 \% \mathrm{Cl}-35$ to -1$)$, adjusted $\mathrm{p}=0.035)$. Among those receiving $400 \mu \mathrm{g}$ daily there was a difference between the mean $(95 \% \mathrm{Cl})$ morning PEF $(\mathrm{l} / \mathrm{min})$ in smokers and non-smokers $(-25(95 \% \mathrm{Cl}-45$ to -4$)$, adjusted $\mathrm{p}=0.019)$ and in the number of asthma exacerbations ( $6 v 1$ in smokers and non-smokers, respectively, $p=0.007)$. These differences were reduced between smokers and non-smokers receiving $2000 \mu \mathrm{g}$ inhaled beclomethasone daily.

Conclusions: Compared with non-smokers, smokers with mild persistent asthma are insensitive to the therapeutic effect of low dose inhaled corticosteroid treatment administered for a 12 week period. The disparity of the response between smokers and non-smokers appears to be reduced with high dose inhaled corticosteroid. These findings have important implications for the management of individuals with mild asthma who smoke.
\end{abstract}

A sthma guidelines recommend inhaled corticosteroids as the most effective anti-inflammatory treatment for chronic asthma. ${ }^{12}$ Inhaled corticosteroids in asthma have been shown to reduce symptoms and exacerbation rates, to improve lung function, ${ }^{34}$ and to decrease the risk of death from asthma. ${ }^{45}$ Most clinical trials have been conducted on non-smokers with asthma and have excluded active smokers. The influence of smoking status on the therapeutic response to corticosteroids has not been investigated until recently. Two randomised controlled trials have found that the efficacy of short term inhaled or oral corticosteroid treatment was impaired in smokers with chronic asthma. ${ }^{67}$ This finding is potentially of considerable importance for the management of adults with asthma since approximately $25 \%$ of them are current smokers. ${ }^{8-10}$ Smoking in asthma is associated with an increase in asthma symptoms, ${ }^{11}$ a faster decline in forced expiratory volume in 1 second $\left(\mathrm{FEV}_{1}\right)$ over time, ${ }^{12}$ and a higher mortality rate after admission with a near fatal asthma attack. ${ }^{13}$

A study was undertaken to assess the efficacy of inhaled corticosteroid treatment when given for a longer duration than previous studies and at different doses. Our hypothesis was that the therapeutic response to inhaled corticosteroids would be reduced in smokers with asthma compared with non-smokers, despite 12 weeks duration of inhaled corticosteroid treatment. If smokers with asthma are found to be insensitive to inhaled corticosteroid treatment, this will have significant implications for the management of these patients who may require alternative or additional treatments to control airway inflammation.

\section{METHODS}

Subjects

Subjects with chronic asthma (current smokers and nonsmokers) aged 18-60 years were recruited from general practices and a hospital clinic. Asthma was diagnosed by American Thoracic Society criteria. ${ }^{14}$ Subjects were receiving a maximum of $500 \mu \mathrm{g}$ daily of beclomethasone or equivalent and had an $\mathrm{FEV}_{1}$ over $50 \%$ predicted. All were symptomatic, defined as having one or more of the following: a validated asthma control questionnaire score $^{15}$ of six or more (maximum 36); reversibility of $\mathrm{FEV}_{1}$ of $12 \%$ or more ${ }^{1}$ after $400 \mu \mathrm{g}$ inhaled salbutamol; diurnal peak expiratory flow (PEF) variability of $15 \%$ on four or more days during the run-in period. ${ }^{16}$ Subjects with $\mathrm{FEV}_{1}$ of $80 \%$ predicted or less post bronchodilator and $\mathrm{FEV}_{1} / \mathrm{FVC} 70 \%$ or less had to demonstrate either reversibility of $\mathrm{FEV}_{1}$ or diurnal $\mathrm{PEF}$ variability as described above. Smoking participants were cigarette smokers with a minimum smoking history of 5 pack-years (1 pack-year equates to smoking 20 cigarettes daily for 1 year). Non-smokers had either never smoked or had stopped smoking cigarettes over 5 years ago and had smoked 5 pack-years or less. Subjects were excluded if they had a respiratory tract infection or needed oral corticosteroids within the preceding 6 weeks.

All participants gave written informed consent. The multicentre research ethics committee for Scotland and appropriate local research ethics committees granted ethical approval.

\section{Study design and assignment}

This was a randomised, double blind, parallel group study comparing the efficacy of $400 \mu \mathrm{g}$ or $2000 \mu \mathrm{g}$ daily inhaled beclomethasone in smokers and non-smokers. Study participants took four puffs twice daily of inhaled beclomethasone from a breath activated pressurised device (Easi-Breathe, IVAX Pharmaceuticals, UK). An independent pharmacist

Abbreviations: $\mathrm{FEV}_{1}$, forced expiratory volume in 1 second; $\mathrm{PEF}$, peak expiratory flow 
overlabelled identical inhalers. The treatment group was assigned from a computer generated list of randomisation numbers. Researchers and participants were blinded to allocation and had no access to the randomisation code held by the Data Centre until completion of the study. Smokers and non-smokers were recruited at approximately the same rate to avoid seasonal confounding. Subjects entered a 2 week run-in where they continued their usual asthma medication and recorded PEF twice daily. Study visits took place 2, 6, and 12 weeks after randomisation. Spirometric parameters were measured before and after administration of salbutamol $400 \mu \mathrm{g}$ from a large spacer device and a validated asthma control questionnaire was completed..$^{15}$ At week 12, returned inhaler canisters were weighed as an assessment of compliance. ${ }^{6}$

\section{Measurements}

PEF was measured twice daily (mini-Wright meter, Clement Clark, UK or MicroPeak, Micro Medical Ltd, UK) and recorded in a diary card along with reliever inhaler use. Spirometric parameters were recorded using a dry wedge spirometer (Vitalograph, Buckingham, UK) following American Thoracic Society guidelines. ${ }^{18}$ Serum cotinine levels were assayed using a commercially available assay (Cozart Biosciences, Abingdon, UK) to confirm smoking status. Total IgE and specific IgE to house dust mite, grass pollen, and cat dander were assayed by the Unicap 100 system (Pharmacia, Uppsala, Sweden). Total IgE levels of over $120 \mathrm{IU} / \mathrm{ml}$ and specific IgE levels of more than $0.35 \mathrm{IU} / \mathrm{ml}$ were considered raised. When specific IgE was raised, an individual was considered atopic. ${ }^{19}$ Severe exacerbations of asthma were defined as a deterioration requiring a course of oral corticosteroid and a mild exacerbation as a fall in morning PEF of $\geqslant 20 \%$ from their baseline morning PEF on two consecutive days. ${ }^{20}$ Participants used their reliever inhaler during exacerbations but were advised not to double the inhaled corticosteroid dose. Attending doctors prescribed courses of oral corticosteroids where necessary.

\section{Statistical analysis}

The primary end point was the mean of the morning PEF measurements as taken from 14 days of diary recording before each study visit. The mean was only calculated if there were three days of completed data within that period. Secondary end points included: evening PEF, exacerbations of asthma, daily reliever inhaler use, spirometric data, and the asthma control questionnaire score. Baseline characteristics of smokers and non-smokers were compared by $\chi^{2}$ tests, $t$ tests, or Wilcoxon tests. For the continuous end points, changes were calculated at 2, 6, and 12 weeks for the primary end point and at 12 weeks for the secondary end points.

Since groups of smoking and non-smoking participants would have different risk profiles, we attempted to reduce confounding by statistical adjustment. We modeled the effect of all candidate variables at baseline upon the mean morning PEF at 12 weeks. Variables were included in the models as "possible confounders" that were significant at the $20 \%$ level. Thus, weak confounders were not erroneously excluded from the analyses. The adjusted analyses of smoking were carried by normal linear models adjusting for baseline, treatment (as a design factor), and the chosen confounders. These confounders were used in all adjusted analyses. An interaction test was used to assess whether the effect of smoking was different for the two doses of inhaled beclomethasone. The occurrence of asthma exacerbations was compared by $\chi^{2}$ tests. Further analyses were carried out within the subgroups defined by treatment group. The intended power of the study was $80 \%$ (at the $5 \%$ level) to detect a mean treatment difference of $20 \mathrm{l} / \mathrm{min}$ in PEF measurements and standard deviation of the difference in PEF measurements of $40 \mathrm{l} / \mathrm{min}$. We attempted to recruit a sample size of 64 patients per group (128 in total).

\section{RESULTS}

5421 asthmatic patients from 54 practices were invited to participate between May 2002 and December 2003 (fig 1). Screening visits were arranged for 303 volunteers: 152 did not fulfil the inclusion criteria and 56 decided not to take part or did not attend; 95 individuals were randomised, three withdrew because of non-asthma related illnesses, two were lost to follow up, and one decided not to take part.

There were no significant differences in age, baseline $\mathrm{FEV}_{1}$ $\%$ predicted before and after salbutamol, $\mathrm{FEV}_{1} / \mathrm{FVC} \%$ after salbutamol, and total IgE between smokers with asthma and non-smokers with asthma (table 1). The smoking group had a higher symptom score, a shorter history of asthma, and fewer were atopic. The improvement in $\mathrm{FEV}_{1}$ after salbutamol was less in smokers than in non-smokers. However, reversibility to salbutamol did not predict the response to corticosteroid $(\mathrm{p}=0.38)$.

There was an improvement in the morning PEF in the nonsmoking group (table 2) but little change in the morning PEF measurements in the smoking group. The difference between the combined 400 and $2000 \mu \mathrm{g}$ doses in the smoking and non-smoking groups was apparent at each visit after PEF was adjusted for duration of asthma, inhaled corticosteroid at baseline, sex, baseline morning PEF, baseline evening PEF, atopy, $\mathrm{FEV}_{\mathrm{l}} / \mathrm{FVC}$ ratio pre-salbutamol, and treatment group. After 12 weeks the smoking and non-smoking groups were dissimilar (mean difference -18 (95\% CI -35 to -1 ), adjusted $\mathrm{p}=0.035)$. The non-smoking asthmatics showed greater improvement in symptom scores by 12 weeks. There were no other differences in secondary outcome measures (table 3).

There was an improvement in the morning PEF values of non-smoking asthmatics receiving $400 \mu \mathrm{g}$ daily beclomethasone but not in smokers (fig 2, table 2). By 12 weeks there was a large difference between the groups receiving $400 \mu \mathrm{g}$ (mean difference $-25 \quad(95 \%$ CI -45 to -4$)$, adjusted $\mathrm{p}=0.019)$. Smokers receiving lower dose beclomethasone had more exacerbations of asthma than non-smokers ( $6 v 1$, $p=0.0067$ ). One smoker required oral corticosteroid. There was some evidence of greater improvement in the evening PEF in non-smokers after 12 weeks ( $10.5 \mathrm{l} / \mathrm{min})$ compared with smokers $(-12.1 \mathrm{l} / \mathrm{min}$; mean difference -18 (95\% CI -38 to 3$)$, adjusted $p=0.088)$, and in reduction of reliever inhaler use (mean difference 2 (95\% CI 0 to 4 ), adjusted $\mathrm{p}=0.057)$.

There was an improvement in the morning PEF values of non-smoking asthmatics receiving $2000 \mu \mathrm{g}$ daily beclomethasone and there was a smaller improvement in the morning PEF values of the smoking group (fig 2, table 2). We did not find a difference in morning PEF values or exacerbation rates of those receiving higher dose beclomethasone between smokers and non-smokers ( $1 \vee 2, \mathrm{p}=0.661)$; one smoker required oral corticosteroid treatment. There was a difference between the symptom scores at 12 weeks (mean difference 1 ( $95 \%$ CI 0 to 2 ), adjusted $p=0.025)$. We did not see any difference between the smoking asthma patients receiving $400 \mu \mathrm{g}$ or $2000 \mu \mathrm{g}$ daily. We carried out a test of interaction to assess whether the effect of smoking was different for the two doses; this test gave a p value of 0.43 .

There was no difference in compliance, assessed by weight of returned canisters and by self-assessment at study visits, between the smoking and non-smoking groups. There was no difference between the number of completed days of PEF measurements present in smokers and non-smokers diary 


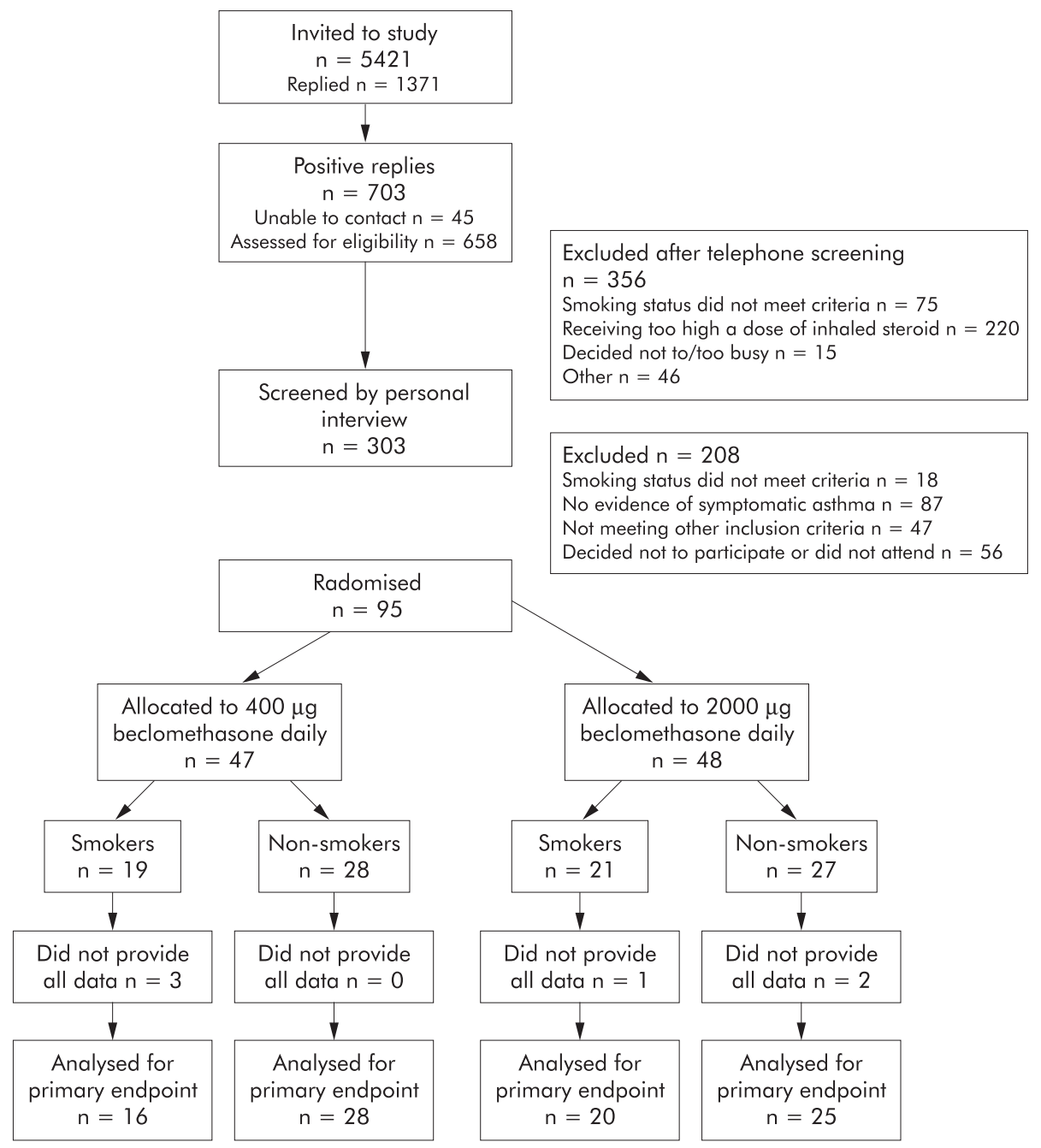

Figure 1 Trial profile.

Table 1 Baseline characteristics of asthmatic smokers and non-smokers by randomisation dose

\begin{tabular}{|c|c|c|c|c|c|c|}
\hline & \multicolumn{3}{|l|}{ Smokers $(n=40)$} & \multicolumn{3}{|c|}{ Non-smokers $(n=55)$} \\
\hline & $400 \mu \mathrm{g}$ & $2000 \mu \mathrm{g}$ & Total & $400 \mu \mathrm{g}$ & $2000 \mu \mathrm{g}$ & Total \\
\hline Age (years) & $44(8)$ & $48(17)$ & $46(13)$ & $42(11)$ & $43(16)$ & $43(14)$ \\
\hline $\operatorname{Sex}(M / F)$ & $8 / 11$ & $6 / 15$ & $14 / 26$ & $12 / 16$ & $17 / 10$ & $29 / 26$ \\
\hline $\begin{array}{l}\text { Taking inhaled corticosteroid at } \\
\text { baseline, } n(\%)\end{array}$ & $7(37 \%)$ & $9(43 \%)$ & $16(40 \%)^{*}$ & $18(64 \%)$ & $16(59 \%)$ & $34(62 \%)$ \\
\hline $\begin{array}{l}\text { Median (IQR) } \mu \mathrm{g} / \text { day equivalent to } \\
\text { beclomethasone }\end{array}$ & $0(0-200)$ & $0(0-400)$ & $0(0-300)$ & $200(0-400)$ & $200(0-400)$ & $200(0-400)$ \\
\hline Median (IQR) duration of asthma (years) & $8(4-16)$ & $12(6-27)$ & $9(5-21)^{*}$ & $19(8-26)$ & $18(10-27)$ & $18(10-27)$ \\
\hline Pack years smoked & $28(19)$ & $23(10)$ & $25(15)^{*}$ & $0(0)$ & $3(2)$ & $3(2)$ \\
\hline Median (IQR) serum cotinine $(\mathrm{ng} / \mathrm{ml})$ & $285(180-351)$ & $298(134-325)$ & $287(164-344) \dagger$ & $1(1-2)$ & $2(1-2)$ & $2(1-2)$ \\
\hline Atopic (specific lgE positive), n (\%) & $8(42 \%)$ & $10(53 \%)$ & $18(47 \%) \dagger$ & 20 (71\%) & $24(92 \%)$ & $44(81 \%)$ \\
\hline Median (IQR) total lgE (IU/ml) & $149(32-567)$ & $40(24-269)$ & $54(30-372)$ & $96(32-238)$ & $148(72-208)$ & $117(49-213$ \\
\hline Reliever inhaler (puffs/day) & $4(3)$ & $4(2)$ & $4(3)$ & $2(2)$ & $2(1)$ & $2(2)$ \\
\hline $\mathrm{FEV}_{1} \%$ predicted pre-salbutamol & $87(11)$ & $85(14)$ & $86(13)$ & $86(17)$ & $84(16)$ & $85(16)$ \\
\hline $\mathrm{FEV}_{1} \%$ predicted post-salbutamol & 91 (11) & $91(15)$ & $91(13)$ & $95(17)$ & $95(15)$ & $95(16)$ \\
\hline $\mathrm{FEV}_{1} / \mathrm{FVC}$ post-salbutamol (\%) & 75 (7) & $73(9)$ & $74(8)$ & 76 (7) & $72(9)$ & $74(8)$ \\
\hline Improvement in $\mathrm{FEV}_{1}$ after salbutamol (ml) & $130(170)$ & $170(150)$ & $150(160) t$ & $300(200)$ & $380(200)$ & $340(200)$ \\
\hline PEF morning (I/min) & 403 (93) & $374(86)$ & $388(90)^{*}$ & 427 (77) & $466(108)$ & 446 (94) \\
\hline PEF night $(1 / \mathrm{min})$ & 422 (101) & 409 (102) & $415(101)^{*}$ & 440 (82) & $484(107)$ & 461 (97) \\
\hline Asthma control score & $1.7(0.96)$ & $2.1(0.63)$ & $1.9(0.82) \dagger$ & $1.1(0.78)$ & $1(0.73)$ & $1.1(0.75)$ \\
\hline
\end{tabular}


Table 2 Comparison of smokers and non-smokers with asthma: morning peak expiratory flow (PEF) measurements at 2, 6 and 12 weeks after receiving inhaled beclomethasone

\begin{tabular}{|c|c|c|c|c|}
\hline & \multicolumn{2}{|c|}{ Mean (SD) change } & \multirow[b]{2}{*}{$\begin{array}{l}\text { Adjusted difference } \\
(95 \% \mathrm{Cl})\end{array}$} & \multirow[b]{2}{*}{$\begin{array}{l}\text { Adjusted } \\
\mathrm{p} \text { value }\end{array}$} \\
\hline & Smokers & Non-smokers & & \\
\hline \multicolumn{5}{|c|}{ Beclomethasone $400 \mu \mathrm{g}$ daily } \\
\hline$\Delta$ Morning PEF & $-10(21)$ & $7(21)$ & $\begin{array}{l}-17(-28 \text { to }-5) \\
\text { [unadjusted }-17(-30 \text { to }-4)]\end{array}$ & $\begin{array}{l}0.0062 \\
\text { [unadjusted } 0.011 \text { ] }\end{array}$ \\
\hline 6 weeks & $n=16$ & $\mathrm{n}=28$ & & \\
\hline$\Delta$ Morning PEF & $-11(43)$ & $13(28)$ & $\begin{array}{l}-26(-46 \text { to }-5) \\
{[\text { unadjusted }-23(-45 \text { to }-2)]}\end{array}$ & $\begin{array}{l}0.0146 \\
\text { [unadjusted } 0.036 \text { ] }\end{array}$ \\
\hline 12 weeks & $n=16$ & $n=28$ & & \\
\hline$\Delta$ Morning PEF & $-6(42)$ & $19(29)$ & $\begin{array}{l}-25(-45 \text { to }-4) \\
\text { [unadjusted }-25(-46 \text { to }-3)]\end{array}$ & $\begin{array}{l}0.0197 \\
\text { [unadjusted 0.025] }\end{array}$ \\
\hline \multicolumn{5}{|c|}{ Beclomethasone $2000 \mu \mathrm{g}$ daily } \\
\hline 2 weeks & $\mathrm{n}=21$ & $\mathrm{n}=23$ & & \\
\hline$\Delta$ Morning PEF & $8(25)$ & $16(33)$ & $\begin{array}{l}-13(-41 \text { to } 16) \\
\text { [unadjusted }-8(-26 \text { to } 10)]\end{array}$ & $\begin{array}{l}0.38 \\
\text { [unadjusted } 0.36 \text { ] }\end{array}$ \\
\hline 6 weeks & $\mathrm{n}=18$ & $n=24$ & & \\
\hline$\Delta$ Morning PEF & $13(26)$ & $19(29)$ & $\begin{array}{l}-19(-48 \text { to } 10) \\
\text { [unadjusted }-6(-23 \text { to } 11)]\end{array}$ & $\begin{array}{l}0.19 \\
\text { [unadjusted } 0.49 \text { ] }\end{array}$ \\
\hline 12 weeks & $n=20$ & $\mathrm{n}=25$ & & \\
\hline$\Delta$ Morning PEF & $11(31)$ & $18(40)$ & $\begin{array}{l}-15(-50 \text { to } 21) \\
\text { [unadjusted }-7(-29 \text { to } 15)]\end{array}$ & $\begin{array}{l}0.40 \\
\text { [unadjusted } 0.50 \text { ] }\end{array}$ \\
\hline \multicolumn{5}{|c|}{ Beclomethasone $400 \mu \mathrm{g}$ and $2000 \mu \mathrm{g}$ combined results } \\
\hline 2 weeks & $n=39$ & $\mathrm{n}=51$ & & \\
\hline$\Delta$ Morning PEF & $0(25)$ & $11(27)$ & $\begin{array}{l}-12(-24 \text { to } 0) \\
\text { [unadjusted }-11(-23 \text { to } 0)]\end{array}$ & $\begin{array}{l}0.058 \\
\text { [unadjusted 0.042] }\end{array}$ \\
\hline 6 weeks & $\mathrm{n}=34$ & $\mathrm{n}=52$ & & \\
\hline$\Delta$ Morning PEF & $2(37)$ & $16(28)$ & $\begin{array}{l}-17(-32 \text { to }-2) \\
\text { [unadjusted }-14(-28 \text { to } 0)]\end{array}$ & $\begin{array}{l}0.0238 \\
\text { [unadjusted 0.054] }\end{array}$ \\
\hline 12 weeks & $n=36$ & $n=53$ & & \\
\hline$\Delta$ Morning PEF & $3(37)$ & $19(34)$ & $\begin{array}{l}-18(-35 \text { to }-1) \\
\text { [unadjusted }-15(-30 \text { to } 0)]\end{array}$ & $\begin{array}{l}0.0346 \\
\text { [unadjusted 0.049] }\end{array}$ \\
\hline
\end{tabular}

cards. Although the study was not powered to detect differences in exacerbation rates as this was a secondary end point, inclusion of the data was considered important as there was a trend to a difference in exacerbation rates in smokers and non-smokers on low dose beclomethasone but not on the high dose. All participants who experienced exacerbations continued in the study and recovered within 7 days. No serious adverse events occurred during the study.

\section{DISCUSSION}

This study has shown that smokers with asthma had a reduced therapeutic response to inhaled corticosteroids over a 3 month period compared with non-smokers. Furthermore, we established that this reduced response is particularly marked in those receiving a low dose of inhaled corticosteroid. Smokers with asthma receiving $400 \mu \mathrm{g}$ daily inhaled beclomethasone did not show any improvement in morning $\mathrm{PEF}$, in contrast to non-smokers. The greater number of mild exacerbations of asthma experienced by smokers on lower dose inhaled beclomethasone supports our conclusion of corticosteroid insensitivity in smokers with asthma.

Participants receiving $2000 \mu \mathrm{g}$ daily inhaled beclomethasone had improved morning PEF measurements, although the change was greater for non-smokers. We did not find any difference between the outcome measures of the smoking and non-smoking asthmatic groups at this higher dose of

Table 3 Comparison of smokers and non-smokers with asthma: all other outcome measures (evening PEF, puffs of reliever inhaler, asthma control questionnaire score, $\mathrm{FEV}_{1}$ pre-salbutamol)

\begin{tabular}{|c|c|c|c|c|}
\hline & \multicolumn{2}{|c|}{ Mean (SD) change } & \multirow[b]{2}{*}{$\begin{array}{l}\text { Adjusted difference } \\
(95 \% \mathrm{Cl})\end{array}$} & \multirow[b]{2}{*}{ Adjusted $\mathrm{p}$ value } \\
\hline & Smokers & Non-smokers & & \\
\hline $\begin{array}{l}12 \text { weeks } \\
\Delta \text { Evening PEF }(1 / \mathrm{min})\end{array}$ & $\begin{array}{l}\mathrm{n}^{*}=36 \\
-3(36)\end{array}$ & $\begin{array}{l}n=53 \\
11(32)\end{array}$ & $\begin{array}{l}-14(-31 \text { to } 3) \\
\text { [unadjusted }-13(-28 \text { to } 1)]\end{array}$ & $\begin{array}{l}0.09 \\
\text { [unadjusted 0.07] }\end{array}$ \\
\hline $\begin{array}{l}\Delta \text { puffs per day of reliever } \\
\text { inhaler }\end{array}$ & $\begin{array}{l}\mathrm{n}=29 \\
0(2)\end{array}$ & $\begin{array}{l}n=37 \\
0(2)\end{array}$ & $\begin{array}{l}1(0 \text { to } 2) \\
\text { [unadjusted } 0(-0.5 \text { to } 1) \text { ] }\end{array}$ & $\begin{array}{l}0.08 \\
\text { [unadjusted } 0.39 \text { ] }\end{array}$ \\
\hline$\Delta$ questionnaire score & $\begin{array}{l}n=34 \\
0(1)\end{array}$ & $\begin{array}{l}n=53 \\
0(1)\end{array}$ & $\begin{array}{l}1(0 \text { to } 1) \\
\text { [unadjusted } 0(-0.3 \text { to } 0.3)]\end{array}$ & $\begin{array}{l}0.0130 \\
\text { [(unadjusted } 0.80 \text { ] }\end{array}$ \\
\hline$\Delta \mathrm{FEV}_{1}$ pre-salbutamol & $\begin{array}{l}n=35 \\
0(0)\end{array}$ & $\begin{array}{l}n=53 \\
0(0)\end{array}$ & $\begin{array}{l}-0.08(-0.2 \text { to } 0.06) \\
\text { [unadjusted } 0(-0.2 \text { to } 0.03) \text { ] }\end{array}$ & $\begin{array}{l}0.26 \\
\text { [unadjusted } 0.14 \text { ] }\end{array}$ \\
\hline
\end{tabular}




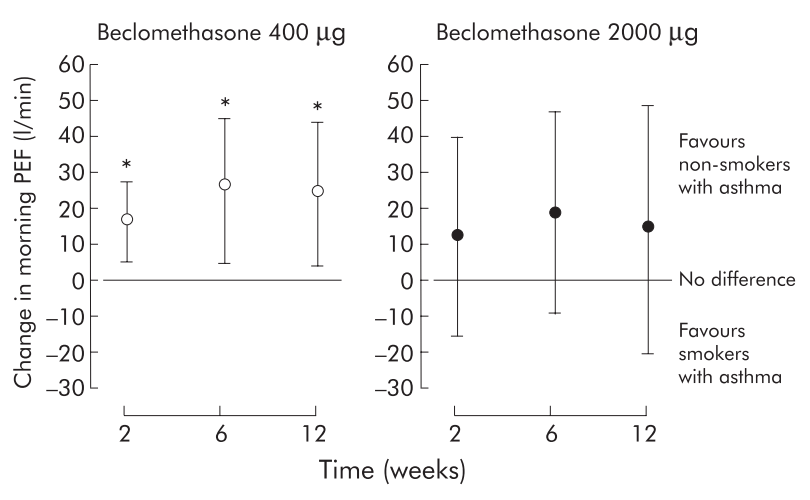

Figure 2 Mean $(95 \% \mathrm{Cl})$ difference between non-smokers and smokers with asthma in change in morning PEF $(1 / \mathrm{min})$ on different doses of inhaled beclomethasone. ${ }^{*} p<0.01$ for smokers with asthma $v$ nonsmokers with asthma.

medication. The improvement in the morning PEF level of smokers may indicate that their insensitivity to corticosteroid medication is being overcome by the administration of higher dose medication. The similar numbers of exacerbations of asthma between smokers and non-smokers receiving this higher dose supports this hypothesis. However, the lack of any demonstrable difference between the smoking and nonsmoking asthmatics receiving $2000 \mu \mathrm{g}$ daily inhaled beclomethasone must be interpreted with caution as the subgroups included fewer patients than originally planned and the interaction test to assess whether the effect of smoking was different for the two doses of treatment was not significant.

These findings extend the results from two short term randomised controlled trials that found the efficacy of corticosteroid treatment was impaired in smokers with chronic asthma. ${ }^{67}$ In the study by Chaudhuri et al, ${ }^{7}$ after 2 weeks of oral prednisolone active cigarette smokers with more severe asthma than those included in the current study had a significantly reduced therapeutic response compared with non-smokers with asthma. Similarly, Chalmers et $a l^{6}$ reported a reduced benefit from inhaled fluticasone administered for 3 weeks in smokers with asthma compared with non-smokers. A post hoc analysis of a randomised clinical trial comparing inhaled budesonide or theophylline noted reduced efficacy of inhaled budesonide among smokers with asthma compared with non-smokers with asthma. ${ }^{21}$ In this study we confirmed that smokers with mild asthma have an impaired response to inhaled corticosteroids at a low dose. In addition, the findings suggest that this insensitivity may be overcome by inhaled corticosteroids given at a higher dose after 12 weeks.

This study included all subjects with a physician's diagnosis of asthma because these are treated for mild asthma in the community. It can be difficult to distinguish smokers with asthma from those with early chronic obstructive pulmonary disease (COPD) who might be less responsive to inhaled corticosteroids. However, smokers with asthma fulfilled the clinical criteria for the diagnosis of asthma and had mean baseline post-bronchodilator $\mathrm{FEV}_{1}$ of $91 \%$ predicted and mean baseline post-bronchodilator $\mathrm{FEV}_{1} /$ FVC of $74 \%$. These spirometric values are well above the upper range for mild COPD. ${ }^{22}$ Taken together, we believe that smokers with asthma are clearly distinct from subjects with COPD.

It is interesting that smokers with asthma were less likely to be atopic than non-smokers, although the level of atopy was still higher than that generally seen in healthy volunteers. In a study of risk factors associated with asthma and the onset of cigarette smoking, asthma that developed before starting smoking was associated with atopy whereas asthma that developed after starting smoking was associated with a lower $\mathrm{FEV}_{1}{ }^{23}$ The influence on asthma phenotypes in relation to the timing of smoking onset needs to be studied further.

Compliance with measuring PEF can be a problem in all clinical trials. We attempted to minimise this by emphasising the importance of diary card completion. In future studies electronic recording of PEF may provide more reliable evidence of measurements.

The main implication for asthma management from this study is that smokers with mild persistent asthma do not benefit in the medium term from low dose inhaled corticosteroid treatment compared with non-smokers. The smokers with asthma showed some benefit from high dose inhaled corticosteroid therapy, suggesting relative corticosteroid insensitivity. This study has not compared any intermediary dose of inhaled corticosteroid or additional therapy. However, if smokers with asthma require high doses of inhaled corticosteroids to produce a therapeutic effect, then this puts them at risk of developing long term adverse effects from inhaled corticosteroid treatment. ${ }^{4}$ Smokers should be encouraged to stop smoking, although it is unknown whether smoking cessation will restore corticosteroid responsiveness in asthma. This group of patients may require alternative or additional anti-inflammatory drug treatment.

\section{ACKNOWLEDGEMENTS}

The authors thank the Research and Development Directorate of the Greater Glasgow Primary Care NHS Trust (provided funding support) and, in particular, acknowledge the advice and guidance of Professor Bob Hunter and Brian Rae of that department, Kay Pollock of the Pharmacy Production Unit, Western Infirmary Glasgow; also the Pharmacy Department of Gartnavel General, Glasgow; Biochemistry and Immunology laboratories at the Western Infirmary, Glasgow; Pharmacia for provision of reagents; AstraZeneca (acquisition of peak flow meters); IVAX (assistance with purchase of study inhalers and casings); all the general practitioners and their staff who assisted with their time and energy.

\section{Authors' affiliations}

J E M Tomlinson, J M Thompson, S F Wood, Department of General Practice, University of Glasgow, Glasgow, UK

A D McMahon, Department of Robertson Centre for Biostatistics, University of Glasgow, Glasgow, UK

R Chaudhuri, N C Thomson, Department of Respiratory Medicine, University of Glasgow, Glasgow, UK

This study was funded by Asthma UK (grant number 01/031) and the Chief Scientist Office of the Scottish Executive Health Department.

NCT has been reimbursed by AstraZeneca (AZ), GlaxoSmithKline (GSK), and Schering Plough (SP), the manufacturers of budesonide, beclomethasone and fluticasone and mometasone, respectively, for attending several conferences and has acted as a consultant to GSK and Altana. His department has received research funds for clinical trials from AZ, GSK, Novartis and Merck; SFW has received fees for speaking, chairing or advising from GSK, AZ, SP, Aventis and Pharmacia. The remaining co-authors have no conflicts of interest to declare.

\section{REFERENCES}

1 National Heart, Lung and Blood Institute. National Asthma Education Program: executive summary. Guidelines for the diagnosis and management of asthma, Publication no 97-4051. Bethesda, MD: National Institute of Health, National Asthma Education and Prevention Program, 1997.

2 BTS/SIGN. British guideline on the management of asthma. Thorax 2003;58:i1-i94.

3 Lipworth B. Modern drug treatment of chronic asthma. BM 1999;318:380-4

4 Barnes P, Pedersen S, Busse W. Efficacy and safety of inhaled corticosteroids. New developments. Am J Respir Crit Care Med 1998;157:51-3. 
5 Lanes S, Garcia Rodriguez L, Huerta C. Respiratory medications and risk of asthma death. Thorax 2002;57:683-6.

6 Chalmers GW, Macleod KJ, Little SA, et al. Influence of cigarette smoking on inhaled corticosteroid treatment in mild asthma. Thorax 2002;57:226-30.

7 Chaudhuri R, Livingston E, McMahon AD, et al. Cigarette smoking impairs the therapeutic response to oral corticosteroids in chronic asthma. Am J Respir Crit Care Med 2003; 168:1308-11.

8 Silverman RA, Boudreaux ED, Woodruff PG, et al. Cigarette smoking among asthmatic adults presenting to 64 emergency departments. Chest 2003; 123:1472-9.

9 Walsh U, Wong CA, Cooper S, et al. Morbidity from asthma in relation to regular treatment: a community based study. Thorax 1999;54:296-300.

10 Thomson N, Chaudhuri R, Livingston E. Asthma and cigarette smoking. Eur Respir J 2004;24:822-33

11 Althuis M, Sexton M, Prybylski D. Cigarette smoking and asthma symptom severity among adult asthmatics. J Asthma 1999;36:257-64.

12 Lange P, Parner J, Vestbo J, et al. A 15 year follow-up study of ventilatory function in adults with asthma. N Engl J Med 1998;339:1 194-200.

13 Marquette C, Saulnier F, Leroy O, et al. Long-term prognosis of near-fatal asthma. Am Rev Respir Dis 1992;146:76-81.

14 American Thoracic Society. Standards for the diagnosis and care of patients with chronic obstructive pulmonary disease (COPD) and asthma. Am Rev Respir Dis 1987; 136:225-34.
15 Juniper $E, O^{\prime} B y r n e ~ P$, Roberts J. Measuring asthma control in group studies: do we need airway calibre and rescue $\beta_{2}$-agonist use. Respir Med $2001 ; 95: 319-23$

16 Venables K, Burge PS, Davison A, et al. Peak flow rate records in surveys: reproducibility of observer's reports. Thorax 1984;39:828-32.

17 Juniper E, O'Byrne P, Guyatt G, et al. Development and validation of a questionnaire to measure asthma control. Eur Respir J 1999;14:902-7.

18 American Thoracic Society. Standardisation of spirometry: 1987 update. Am Rev Respir Dis 1987;136:1285-98.

19 Johansson S, Hourihane J, Bousquet J, et al. A revised nomenclature for allergy: an $\mathrm{EAACl}$ position statement from the $\mathrm{EACCl}$ nomenclature task force. Allergy 2001;56:813-49.

20 Reddel H, Salome C, Peat J, et al. Which index of peak expiratory flow is most useful in the management of stable asthma? Am J Respir Crit Care Med 1995; 151:1320-5.

21 Pedersen B, Dahl R, Karlstrom R, et al. Eosinophil and neutrophil activity in asthma in one-year trial with inhaled budesonide. Am J Respir Crit Care Med 1996; 153:1519-29.

22 Celli B, MacNee W. Standards for the diagnosis and treatment of patients with COPD: a summary of the ATS/ERS position paper. Eur Respir $J$ 2004;23:932-46

23 Raherison C, Baldi I, Tunon De Lara J, et al. Asthma phenotypes according to the timing of smoking onset in young adults. Int J Tuber Lung Dis 2003;7:84-92.

\section{LUNG ALERT}

Evidence for a genetic susceptibility to lung carcinoma

$\Delta$ Jonsson S, Thorsteinsdottir U, Gudbjartsson DF, et al. Familial risk of lung carcinoma in the Icelandic population. JAMA 2004;292:2977-83

$\mathrm{P}$ revious studies of the genetic epidemiology of lung cancer have suggested a modest (twofold) increased risk associated with a family history of lung cancer. It has been unclear whether the increased risk observed reflected genetic factors specific to lung cancer, genetic modifiers of nicotine addiction (leading to increased tobacco exposure), or shared environmental factors.

Jonsson and colleagues accessed the Icelandic genealogical database (which has population and ancestry data for all Icelanders), the Icelandic Cancer Registry (to identify cases of lung cancer), and the Reykjavik Heart Study (which provided smoking information for a cohort of the studied patients). They found a significant (2-3.5 fold) increased risk of developing lung carcinoma in first degree relatives of patients with lung cancer. This relative risk exceeded the relative risk of smoking.

An increased relative risk of lung cancer was also seen in the second and third degree relatives of probands, again in excess of the relative risk of smoking. Spouses of patients had a slightly increased risk of developing lung cancer but this appears to relate to a common environment; their relative risk of smoking exceeded that of lung cancer.

By controlling for tobacco exposure and demonstrating a rise in relative risk beyond the nuclear family, the investigators present compelling evidence for the existence of specific inherited genetic factors which can contribute to the development of lung cancer. Further studies may outline inheritance patterns and point towards specific gene defects or polymorphisms responsible for the familial association found.

\section{Carlin}

Clinical Research Fellow, Scottish Pulmonary Vascular Unit, Western Infirmary, Glasgow, UK ccarlin@tiscali.co.uk 